\title{
Metaversos e laboratórios virtuais - possibilidades e dificuldades
}

\author{
Marcelo Augusto Rauh Schmitt ${ }^{1}$, Liane Margarida Rockenbach Tarouco ${ }^{2}$ \\ ${ }^{1}$ Escola Técnica - UFRGS - Brasil \\ ${ }^{2}$ Centro Interdisciplinar de Novas Tecnologias na Educação - UFRGS -Brasil \\ schmitt@escolatecnica.ufrgs.br, liane@penta.ufrgs.br
}

\section{Resumo}

Este artigo analisa a utilização do paradigma dos metaversos para a criação de laboratórios virtuais. Parte do princípio de que cursos de engenharia e cursos profissionais de áreas tecnológicas não podem prescindir de práticas pedagógicas em laboratórios e que, portanto, para tais cursos serem ofertados à distância, estas atividades devem estar presentes. O paradigma do metaverso é apresentado como uma alternativa viável para a implementação de laboratórios virtuais que propiciem efetividade na aprendizagem semelhante à dos laboratórios presenciais. Tal idéia é sustentada pela possibilidade de construção de dispositivos virtuais em um ambiente imersivo que permite a comunicação e a colaboração entre todos os envolvidos na atividade laboratorial.

Palavras-chave: laboratório, metaverso, cursos tecnológicos e colaboração.

\begin{abstract}
This paper examines the use of metaverse paradigm in the creation of virtual laboratories. It assumes that engineering courses and vocational courses in the field of technology need pedagogical practices in laboratories and therefore, for such courses to be offered remotely, these activities must occur. The model of metaverse is presented as a feasible alternative for the implementation of virtual laboratories capable to provide effectiveness in learning similar to that of hand-on laboratories. This idea is based on the possibility of creating virtual devices in an immersive environment that allows communication and collaboration between all those involved in laboratory activity.
\end{abstract}

Keywords: laboratory, metaverse, technology courses and collaboration.

\section{Introdução}

As graduações em engenharia apresentam necessidades especiais no que diz respeito à utilização de laboratórios para atividades pedagógicas. Segundo Feisel e Rosa (2005), os laboratórios são parte essencial dos cursos de engenharia desde os primeiros tempos. Há um consenso no meio acadêmico de que tais cursos dependem de atividades práticas realizadas em laboratório para propiciarem uma formação adequada aos seus alunos. O mesmo ocorre nos cursos profissionais das áreas tecnológicas. Tais cursos não podem prescindir de atividades laboratoriais, uma vez que os alunos são formados para atividades eminentemente práticas.

A educação à distância (EAD) traz consigo a impossibilidade de oferecer laboratórios presenciais a todos os alunos, que se encontram distantes uns dos outros e dos próprios campi das Universidades. Para que cursos tecnológicos possam ser ofertados na modalidade à distância, tal limitação tem de ser superada sem que se abdique da prática laboratorial. Necessita-se de um substituto para o laboratório presencial que cumpra o mesmo papel pedagógico.

Uma vez que a Internet tem se tornado um canal fundamental para a implementação da educação à distância, os ambientes virtuais de aprendizagem (AVAs) 
disseminaram-se como a principal ferramenta de suporte à aprendizagem. Esses ambientes constituem-se no arcabouço utilizado por professores para disponibilização de material didático aos alunos e para a realização da comunicação com e entre eles. Portanto, a expansão do ensino à distância está necessariamente relacionada com a evolução destas ferramentas, que devem ser de fácil utilização tanto para professores como para estudantes. Uma interface amigável é um aspecto fundamental para que um sistema seja adotado com satisfação pelos seus usuários e transforme-se em uma ferramenta usual. Como exemplos de AVAs típicos podem ser citados:
a. Moodle
b. Sakai
c. Blackboard
d. WebCT

Alguns destes softwares são comercializados e outros são disponibilizados gratuitamente através de licenças de domínio público. Embora empresas e desenvolvedores procurem apresentar as diferenças entre as plataformas, estes ambientes, de forma geral, são constituídos por três categorias de ferramentas: aquelas que permitem ao professor disponibilizar materiais de aprendizagem para os alunos; outras que servem para promover a comunicação entre os membros do grupo com vistas a incentivar a aprendizagem colaborativa; e, por último, as que possibilitam realizar o controle das atividades realizadas pelos alunos.

Apesar dos tipos de ferramentas disponíveis, na maioria das vezes, tais ambientes têm sido utilizados pelos professores apenas como um espaço para disponibilizar material a ser estudado pelos alunos. E, muitas vezes, o material se resume a textos para leitura, sem que sejam explorados objetos de aprendizagem com animações, simulações e interação, tornando o ambiente virtual de aprendizagem algo semelhante a uma loja de fotocópia. O AVA substitui o "xerox"”. Mais especificamente, o AVA poderia receber o nome de "xerox eletrônico". Kemp e Livingstone (2006) apontam claramente que, na maior parte das vezes, o conteúdo educacional é armazenado em documentos estáticos, e pouco se faz uso de interatividade.

Esta subutilização ocorre porque, ao longo do tempo, a escola tem replicado um processo de ensino no qual o professor é o transmissor de todo o conhecimento e o aluno, um receptor passivo. De um modo geral, as gerações sucedem-se e esta prática se repete. Repete-se, inclusive, em cursos que utilizam ambientes virtuais de aprendizagem repletos de ferramentas que permitiriam uma abordagem mais colaborativa. Isto ocorre a despeito do fato de que as práticas sociais e a colaboração sejam reconhecidas como aspectos importantes no favorecimento do processo de aprendizagem, permitindo que cada participante de um grupo esteja constantemente revendo seus conhecimentos e pontos de vista, podendo então reorganizar e ampliar seus saberes. Morishima et alli (2004) resumem de forma simplificada os benefícios de se utilizar um ambiente de aprendizagem colaborativo através da frase "learning by teaching e learning by observation". Isto é, o aluno aprende na medida em que ensina outros colegas e aprende na medida em que observa outros colegas solucionarem problemas ou ensinarem outros alunos.

Tal situação se torna ainda mais dramática nos cursos de engenharia e em cursos técnicos essencialmente dependentes da prática laboratorial. Uma vez que não é possível prescindir do laboratório, o uso limitado dos ambientes virtuais de aprendizagem leva, muitas vezes, à conclusão de que tais cursos estão excluídos de qualquer possibilidade de oferta à distância. A simplificação do "xerox virtual" que já 
prejudica sobremaneira outros cursos, é catastrófica quando se tem como objetivo a formação tecnológica.

Este artigo salienta a importância do laboratório na formação profissional, tanto como ferramenta para consolidar conceitos e antecipar a prática profissional, como espaço privilegiado para o trabalho colaborativo que potencializa a aprendizagem. Propõe, por isso, a utilização do modelo do metaverso como base para a construção de laboratórios virtuais e de um ambiente de aprendizagem mais rico que substituam o laboratório tradicional.

\section{0 laboratório na formação tecnológica}

A literatura aponta três diferentes tipos de laboratórios comumente utilizados no ensino das engenharias: o laboratório presencial (hands-on lab), o laboratório remoto e o laboratório virtual. O laboratório presencial é aquele utilizado corriqueiramente em cursos presenciais, no qual o aluno manipula diretamente os materiais constitutivos dos experimentos, no mesmo espaço e tempo que seus colegas e na presença do professor. $\mathrm{O}$ laboratório remoto é aquele que se encontra distante do aluno quando de sua utilização. Nesse tipo, a prática ocorre através de alguma interface que realiza a mediação entre o aluno e os materiais e equipamentos. Essa interface permite o controle à distância dos instrumentos e materiais reais que se encontram em lugar distinto daquele ocupado pelo aluno. Por último, o laboratório virtual é aquele baseado em simulações. $\mathrm{O}$ aluno não interage com instrumentos e materiais reais, mas com representações computacionais da realidade.

Para que ocorra a disseminação de cursos à distância em áreas tecnológicas dependentes de laboratórios, é preciso ampliar quantitativa e qualitativamente as soluções em termos de laboratórios remotos e laboratórios virtuais. No entanto, a substituição do laboratório presencial, tradicionalmente utilizado, por laboratórios de outros tipos não é algo aceito pela totalidade da comunidade científica. Há um debate sobre a pertinência de laboratórios presenciais serem substituídos por laboratórios virtuais ou mesmo remotos. Nickerson et alli (2007) apontam que o debate atual a respeito do tema é passional e pouco conclusivo.

De qualquer forma, a literatura não indica que laboratórios virtuais ou remotos não possam ser substitutos de laboratórios presenciais. Ma e Nickerson (2006), ao estudarem a literatura disponível sobre o assunto, concluem que a eficiência relativa dos laboratórios remoto e virtual em relação ao laboratório presencial é raramente explorada por falta de critérios bem definidos; e que não há diferença significativa entre os três tipos, mesmo porque os estudos realizados são em pequena escala. De acordo com Corter et alli (2007), laboratórios remotos e simulados podem ser, pelo menos, tão eficientes quanto os tradicionais (presenciais) no ensino de conceitos específicos. A mistura das três formas já é uma realidade. De fato, os próprios laboratórios presenciais já não são, necessariamente, diretamente manipulados pelos alunos. $\mathrm{O}$ avanço tecnológico já alterou tais laboratórios (Feisel e Rosa, 2005; Peterson e Feisel, 2002). Computadores são utilizados no controle de experimentos, na aquisição de dados e na análise dos resultados. Neste caso, no próprio laboratório presencial ocorre uma mediação entre o aluno e o material ou entre o aluno e os equipamentos disponíveis para uso. Tendo isso em vista, acredita-se que laboratórios virtuais apresentam o potencial de serem alternativas a laboratórios presenciais, mesmo que em caráter de complementaridade e que seu uso e impactos no processo de ensino-aprendizagem necessitam investigação mais aprofundada. 


\section{O laboratório como espaço de colaboração}

Vygotsky, ao conceituar a Zona de Desenvolvimento Proximal, valoriza sobremaneira a questão da colaboração. Ele define a Zona de Desenvolvimento Proximal como a distância entre o nível real de desenvolvimento, que se costuma determinar através da solução independente de problemas, e o nível de desenvolvimento potencial, determinado através da solução de problemas com ajuda. A interação social constitui, pois, uma forma de acessar ampla fonte de dados que enseja ao indivíduo aprender e desenvolver-se. Proporcionar a colaboração nas atividades pedagógicas é ampliar a Zona de Desenvolvimento Proximal criando assim condições para que o nível de desenvolvimento real do estudante seja ampliado em relação ao que teria sido possível mediante um processo de aprendizagem independente $\mathrm{e}$ isolado. A aprendizagem é potencializada quando realizada em um ambiente colaborativo e com a mediação e intervenção de participantes mais competentes. A mediação do professor, bem como as interações com os demais participantes e com o ambiente de aprendizagem, tem impacto positivo para um melhor aproveitamento da Zona de Desenvolvimento Proximal do aluno, ou seja, o nível de desenvolvimento real do aluno pode mais facilmente alcançar aquilo que era apenas uma potencialidade.

O laboratório, nos cursos de tecnologia, não tem apenas a função de promover a constatação prática daquilo que é aprendido na teoria, de ilustrar e validar matéria estudada, ou de antecipar a prática profissional. A colaboração e a comunicação são considerados elementos fundamentais das atividades laboratoriais. Dentre os objetivos dos laboratórios considerados pela ABET (Accreditation Board for Engineering and Technology) estão a comunicação e o trabalho em equipe (Peterson e Feisel, 2002). Lindsay et alli (2007) sustentam que, no laboratório, os estudantes desenvolvem habilidades sociais e de trabalho em equipe. Os trabalhos de Nedic et alli (2003) e Arango et alli (2007) também ressaltam a colaboração e a comunicação como objetivos do laboratório.

Conclui-se, pois, que o papel da prática em laboratório ultrapassa meros aspectos de treino e prática, criando condições para uma salutar prática de trabalho em equipe tão necessário para o futuro exercício profissional dos estudantes. O laboratório é espaço privilegiado de aprendizagem não apenas porque permite a visualização real daquilo que foi ou será visto na teoria, mas porque promove a comunicação e a colaboração. A atividade em laboratório, se bem construída, atinge a potencialidade de desenvolvimento do aluno, isto é, da Zona de Desenvolvimento Proximal do aprendiz. Peterson e Feisel (2002), quando comparam os tipos de laboratório, chegam a afirmar que o fator mais relevante para as diferenças no aprendizado em um laboratório é a colaboração e não a tecnologia.

Logo, laboratórios virtuais que efetivamente promovam a colaboração e a comunicação entre alunos e professores, apresentando ligação clara com os problemas reais que se deseja abordar, são espaços de aprendizagem que permitem alcançar resultados mais coerentes em relação aos objetivos pretendidos para laboratórios presenciais instrucionais. Neste sentido, a busca de ambientes que suportem simultaneamente a prática laboratorial e as atividades colaborativas é relevante. Conforme exposto a seguir, os metaversos apresentam estas características.

\section{0 metaverso como laboratório virtual}


O termo metaverso tem sua origem no livro de ficção científica Snow Crash de Neal Stephenson (1992). A obra apresenta um mundo virtual em que seres humanos interagem uns com os outros através de avatares em um espaço tridimensional (metauniverso). Bainbridge (2007) utiliza o termo mundo virtual para descrever "ambiente eletrônico que mimetiza visualmente espaços físicos complexos, no qual pessoas podem interagir entre si e com objetos, e onde estas pessoas são representadas por personagens animados."

O Second Life é, atualmente, o metaverso mais conhecido. No entanto, existem outros exemplos, tais como Active Worlds e There. As características comuns desses mundos virtuais estabelecem um novo modelo de interface com o usuário que poderá ser utilizado para as mais diversas aplicações e que muito influenciará aquelas que suportam a aprendizagem. A seguir são relacionadas algumas destas características.

- Os participantes do metaverso interagem uns com os outros de acordo com os seus desejos. O metaverso apresenta semelhanças com os Multi User Dungeons (MUDs), ou Role Playing Games (RPGs), mas não há um enredo fechado ou um contexto pré-definido para que ocorra o desenrolar de uma história. Os contextos são construídos dinamicamente. Dessa forma, embora haja um componente lúdico no ambiente, ele não corresponde a um jogo com o objetivo de vencer.

- Metaversos são ambientes predominantemente gráficos. Textos são utilizados para os diálogos, mas o usuário "enxerga" aquilo que está fazendo, "vê" para onde está indo, "pega" aquilo que deseja manusear. Enfim, o usuário realiza ações semelhantes àquelas do mundo físico. Ao invés de entrar em uma página, entra em uma sala.

- No metaverso são utilizados avatares para o estabelecimento de interações entre usuários. Estes avatares são construídos pelos próprios usuários. Assim como no mundo físico, no metaverso os entes que se comunicam apresentam um corpo e este corpo faz parte do processo de interação com o ambiente e com as outras pessoas. A interação ocorre através de uma perspectiva de primeira pessoa (Lombard e Ditton, 1997).

Tais características definem um novo paradigma de interface com o usuário que traz conseqüências na interação entre eles. Interessa o fato de que metaversos têm estimulado a formação de comunidades virtuais que encontram nele um ambiente propício para a troca de idéias. Uma comunidade virtual de aprendizagem é um caso particular de comunidade virtual que também pode se beneficiar das características do metaverso. E um laboratório deve sempre ser uma comunidade de aprendizagem, pois deve sempre ter como característica a colaboração entre os aprendizes e os professores.

Para alguns autores (Nedic et alli, 2003), os laboratórios virtuais não proporcionam a colaboração. Tal afirmação pressupõe que as simulações sejam executadas nos equipamentos de cada aluno, sem contato nenhum com colegas e professores. Isso não é, de modo algum, desejável, já que um componente fundamental da atividade laboratorial se perde: a colaboração. O metaverso apresenta-se como uma ferramenta promissora para resolver tal questão, uma vez que é um ambiente que proporciona duas condições fundamentais para substituir laboratórios presenciais: a interação entre os usuários e a manipulação de dispositivos virtuais previamente definidos (simulações).

A diferença entre dispositivos reais e virtuais não é, necessariamente, um problema no que concerne à efetividade da atividade laboratorial na aprendizagem. Para 
Peterson e Feisel (2002), não é a ligação com o mundo real que faz a diferença entre os tipos de laboratórios, mas a crença sobre esta ligação. O sentimento de presença é determinante na efetividade do laboratório virtual. Tal idéia é também corroborada por Lindsay et alli (2007), que consideram a presença social como fator importante para o sucesso dos alunos e como um desafio para ambientes de ensino à distancia. Está clara, neste contexto, a idéia de presença em ambientes virtuais como definida por Lombart e Ditton (1997) - “a ilusão da não mediação”. Segundo os mesmos autores, a sensação de presença implica tanto em um maior envolvimento quanto em um desempenho melhor na realização de tarefas.

O metaverso apresenta características que propiciam a sensação de presença tais como o ambiente 3D, a perspectiva em primeira pessoa (também citado por Arango et alli, 2007) e a interatividade. A migração de um ambiente cujas interações são suportadas basicamente por texto, ou por diagramas, para outro que tem na emulação do mundo físico o seu fundamento propiciam aos alunos e professores um maior sentimento de imersão, necessário na implementação de laboratórios virtuais. Kemp e Livingstone (2006) afirmam que, comparado com outras ferramentas eletrônicas, no Second Life pode haver um aumento do sentimento de "localização" (being there). Este sentimento é vital para a motivação do aluno. A identidade entre um lugar e o grupo que o freqüenta é inerente ao ser humano. Pode-se perceber que as pessoas apresentam comportamentos distintos conforme o lugar em que se encontram. Os AVAs, com suas estruturas de hiperlinks, não fornecem aos alunos a sensação de lugar, no sentido que este termo tem na vida cotidiana. Já no metaverso é possível construir diversos locais de acordo com a necessidade: uma sala de conferências, um museu, um laboratório, até mesmo uma sala de aula tradicional em que os alunos sentam em suas cadeiras ou um pátio para o recreio. $\mathrm{O}$ aluno não navega mais em uma página para acessar fóruns ou chats a fim de colaborar com o colega; o aluno e seus colegas estão presentes no "lugar" da aula. A colaboração passa a ser percebida como necessária uma vez que ocorre em um espaço percebido como real. Quem propicia essa sensação é justamente a interface diferenciada, característica do novo paradigma.

Além disso, a percepção do papel do outro também concorre para um melhor trabalho colaborativo. Alunos só colaboram na medida em que percebem as contribuições dos colegas, em que fazem arranjos com eles e colocam suas idéias para o outro. Hampel, Selke e Vitt (2005) deixam claro que, no processo de construção de conhecimento, é fundamental que cada aluno esteja ciente das atividades desenvolvidas pelos colegas. A utilização de avatares e a possibilidade de construção de laboratórios dentro do metaverso permitem que o aluno efetivamente perceba o outro e o trabalho deste em um nível superior àquele dos ambientes virtuais de aprendizagem.

Há muitos exemplos de utilização do metaverso Second Life em educação. É possível conhecer uma amostra destes exemplos apresentados no evento denominado Second Life Education Workshop de $2007^{2}$. O Projeto ARCA (figura 1), com a participação da Universidade Federal do Rio Grande do Sul (UFRGS), da Universidade Luterana do Brasil e da Universidade Católica de Pelotas, buscou "ensejar condições para uma aprendizagem significativa através de um ambiente que, usando realidade virtual, permitisse a cooperação" . 

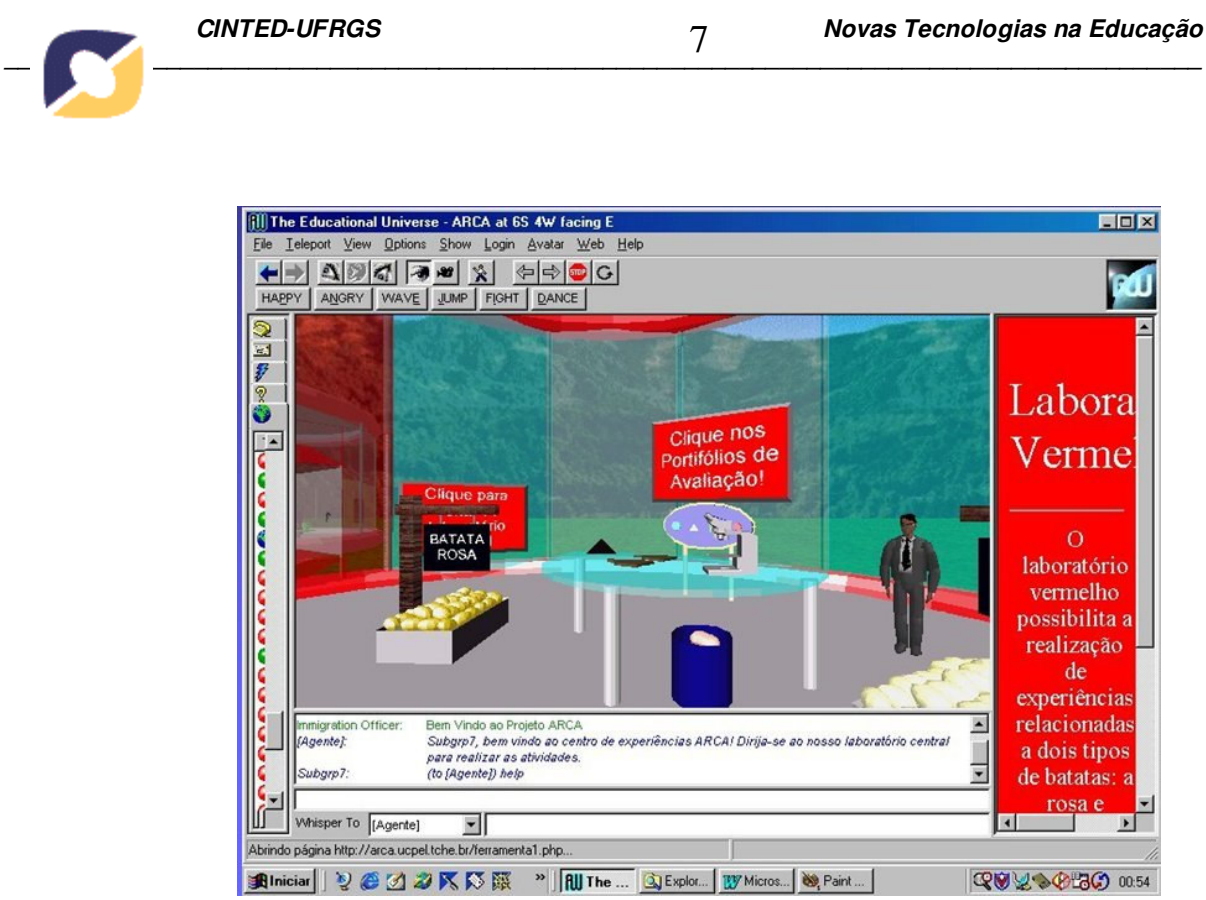

Figura 1: Laboratório virtual do projeto ARCA

Tal projeto fez uso do metaverso conhecido com Active Worlds. Os resultados alcançados permitiram concluir que "ambientes virtuais 3D podem proporcionar uma aprendizagem mais significativa, garantindo a potencialização das relações sociais mediante o uso de avatares e de outros objetos gráficos".

Um dos resultados interessantes alcançados nesta experiência com o metaverso desenvolvido derivou do uso de Agentes Pedagógicos Animados que apóiam o aprendizado humano através da interação com os estudantes no contexto de um ambiente interativo de aprendizagem. Os agentes pedagógicos foram usados neste projeto recebendo uma "materialização" na forma de caracteres animados, assumindo um avatar. O agente estava em permanente diálogo com os estudantes e produzia um comportamento que aparentemente natural com vistas a motivar o estudante, bem como a apoiar sua atividade no laboratório virtual.

Exemplos muito claros do uso de mundos virtuais como laboratórios para aprendizagem são encontrados na Universidade de Stanford ${ }^{4}$. O SUMMIT - Stanford University Medical Media \& Information Technology - é um grupo que se dedica a pesquisar e a criar novas tecnologias para a educação médica, mais especificamente, softwares interativos. Mundos virtuais em 3D foram desenvolvidos para a implementação de laboratórios que simulem situações importantes no dia-a-dia das equipes médicas, sendo utilizados no treinamento de alunos.

SiMEergency (figura 2) é um mundo virtual para o ensino da reanimação cardiopulmonar (RCP) para alunos de ensino médio. O ambiente simula uma típica escola de ensino médio americana. Os alunos e o sujeito com necessidade de atendimento emergencial são avatares. Os alunos colaboram entre si, assumem papéis de liderança e interagem com "o doente" para realizarem os procedimentos necessários ao restabelecimento de um quadro clínico estável. Os resultados publicados no relatório anual de março de $2008^{5}$ indicam um aumento da confiança no enfrentamento de situação semelhante no mundo real e da habilidade para realização da RCP em emergências. Além disso, os estudantes consideraram que tal método de ensino será parte da educação do futuro. 


$-\int \frac{\text { CINTED-UFRGS }}{8} \quad$ Novas Tecnologias na Educação

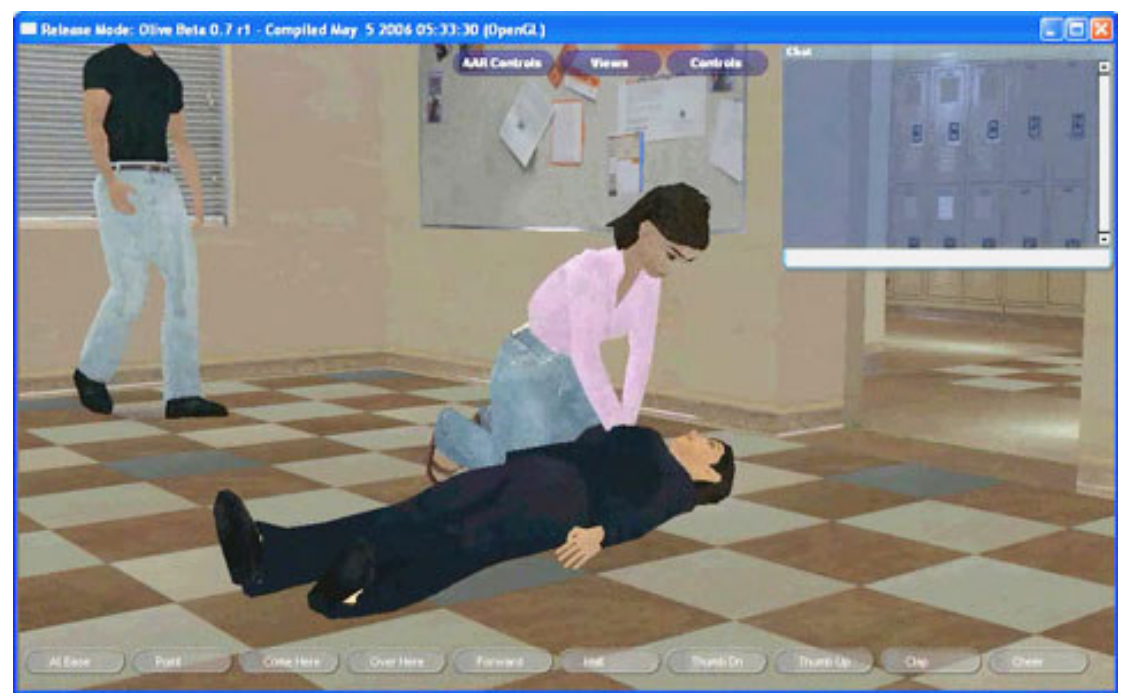

Figura 2

Outro projeto do grupo de pesquisa SUMMIT que segue a mesma linha é o SimTech $^{6}$. Neste caso, foi desenvolvido um ambiente também 3D, multiusuário, que utiliza avatares (perspectiva em primeira pessoa) para o treinamento no atendimento de traumas (figura 3). Os professores e alunos têm à sua disposição um conjunto de cenários. Durante uma sessão de treinamento, os usuários assumem os papéis de médicos e enfermeiros para realizarem o atendimento do paciente virtual. Esta equipe deve se coordenar e colaborar para realizar um correto atendimento médico. Conforme as atitudes tomadas por cada aluno, através de seu avatar, alteram-se os sinais vitais do paciente. Revela-se interessante a possibilidade de que toda a sessão de atendimento seja revista e analisada pelos alunos e pelo professor, permitindo a identificação de eventuais decisões incorretas.

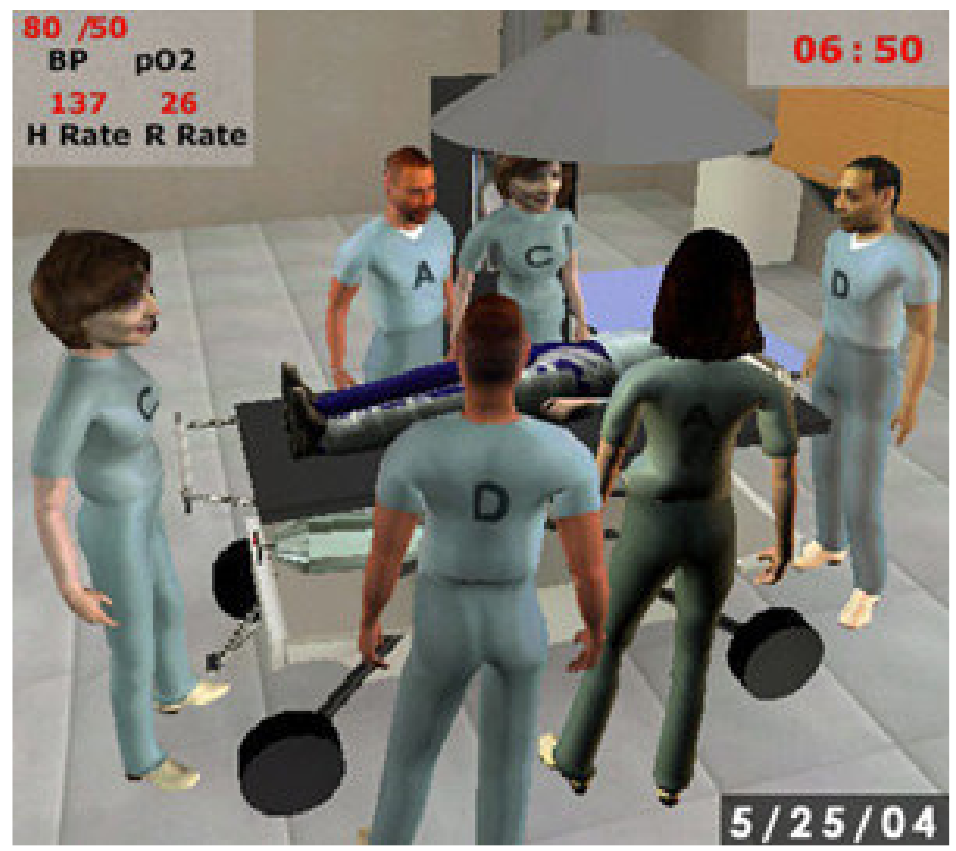

Figura 3 
Estes dois laboratórios criados na Universidade de Stanford para a área de saúde apresentam características de metaverso absolutamente necessárias à implementação de laboratórios virtuais no campo das engenharias. É fundamental a possibilidade de colaboração em um laboratório de aprendizagem. Não basta uma simulação bem feita, o laboratório é o local da experiência coletiva, da aprendizagem colaborativa. Por outro lado, ambiente não pode ser apenas uma espaço para comunicação dissociada do experimento propriamente dito. $\mathrm{O}$ mundo virtual não pode ser apenas um chat com recursos visuais mais requintados, é importante que seja igualmente o espaço do experimento. É o que se percebe nos dois exemplos anteriormente relatados, já que as simulações pressupõem a colaboração das equipes e o atendimento do paciente ocorre no mesmo local da comunicação.

Isto demonstra que metaversos podem trazer um ganho para o desenvolvimento de laboratórios virtuais, ambientes tão necessários em cursos tecnológicos à distância. A utilização de simulações em um ambiente rico socialmente - que permite a comunicação e a colaboração - e a liberação das amarras do texto e mesmo do hipertexto - que proporciona maior imersão no ambiente virtual - traz uma contribuição fundamental para que os laboratórios virtuais cumpram o papel de substituir os laboratórios presenciais. 


\section{Desafios para o futuro próximo}

Hendaoui, Limayem e Thompson (2008), em recente artigo, propõem várias questões sobre os mundos virtuais. Dentre elas, perguntam se o e-learning evoluirá para o v-learning. Isto é, se os atuais AVAs transformar-se-ão em metaversos e passarão a ser veículos para a disponibilização de laboratórios virtuais. Esta evolução depende da resolução de algumas questões ainda presentes nos mundos virtuais atualmente disponíveis. Em primeiro lugar, sistemas deste tipo terão de proporcionar interfaces com respostas mais rápidas. A partir do momento em que se tenta simular o mundo real, é natural que o usuário espere que suas ações ocorram em tempos semelhantes ao que ocorre na realidade. Claypool e Claypool (2006), em artigo sobre jogos online, apresentam a latência do sistema como ponto crucial para o desempenho do jogador. Para eles, a partir do momento em que a reposta do jogo em relação às ações do jogador se degrada, o seu desempenho piora. Reforçam, ainda, que a piora é maior em jogos com avatares, em especial aqueles que apresentam o ambiente na perspectiva da primeira pessoa. O laboratório virtual em metaverso não é um jogo, mas é um ambiente virtual com avatares, no qual o usuário interage na forma de primeira pessoa, e que traz expectativas de resposta do sistema às ações do usuário semelhantes aos jogos online.

A experiência de uso do Second Life em disciplina do Programa de PósGraduação em Informática na Educação na UFRGS, durante do segundo semestre de 2007, revelou a necessidade de conexões rápidas e de computadores com configurações adequadas à aplicação. Isto traz dificuldades, uma vez que alunos e instituições de ensino não necessariamente contam com computadores de última geração e que a velocidade da Internet depende dos diversos enlaces por onde os pacotes trafegam.

Além da questão de infra-estrutura apontada, há também a questão do preparo dos professores para utilização de ambientes cada vez mais complexos. É verdade que os metaversos permitem a construção de objetos que podem formar laboratórios. Mas também é verdade que ferramentas informatizadas tornam-se usuais somente na medida em que são de fácil utilização. Não se deve esperar que um professor de química aprenda uma linguagem para criar um laboratório para seus alunos no metaverso. Há que se disponibilizar, para este professor, um laboratório em que ele possa dispor dos elementos que habitualmente utiliza, tais como tubos de ensaio, reagentes, fogo, etc. Não são apenas os alunos que devem ser conquistados pela imersão que o ambiente proporciona, mas também educador. Se o professor não puder trabalhar no mesmo contexto de abstração que trabalha no mundo físico, o ambiente não estará cumprindo o que promete e será apenas mais uma ferramenta que alguns professores curiosos utilizarão.

Como salientado na introdução este artigo, os professores subutilizam até mesmo os ambientes virtuais de aprendizagem atualmente disponíveis. E isto ocorre também por um componente cultural, pela replicação das práticas da sala de aula tradicional. Tal fato permite identificar que ainda maior será o desafio de capacitar professores e mudar esta cultura estabelecida para que metaversos sejam utilizados para práticas laboratoriais.

\section{Considerações finais}

Não resta dúvida de que o paradigma do metaverso pode contribuir muito para o ensino à distância, especialmente no que diz respeito à implementação de laboratórios essenciais aos cursos de engenharia e aos cursos profissionais de áreas tecnológicas. Sabe-se que metaversos ainda são ambientes que exigem muitos recursos 
computacionais, tanto de máquinas servidoras como de máquinas clientes que ainda não estão disponíveis na maioria das escolas (Kemp e Livingstone, 2006). Da mesma forma, exigem recursos no que diz respeito às redes de computadores. No entanto, os problemas deste tipo têm, habitualmente, sido resolvidos em curto espaço de tempo. Assim, cedo ou tarde, haverá equipamentos que permitirão aos usuários interagirem em metaversos com mais agilidade e precisão, o que poderá tornar o modelo ainda mais atraente para utilização em comunidades virtuais de aprendizagem e, portanto, em laboratórios virtuais utilizados em cursos à distância.

Quando tal momento chegar, os Ambientes Virtuais de Aprendizagem serão diferentes daqueles existentes hoje. Afinal, os AVAs atuais utilizam muitas ferramentas textuais para a interação porque essas são as tecnologias de comunicação disponíveis no momento. Uma vez que o metaverso esteja estabelecido como um espaço privilegiado para a comunicação parece inevitável que tal espaço seja transportado para os AVAs. $\mathrm{Na}$ verdade, não será possível dizer se o metaverso foi transportado para o ambiente virtual de aprendizagem ou se o metaverso assumiu o papel de ambiente virtual de aprendizagem. Acredita-se, isto sim, que o ambiente virtual de aprendizagem será mais um metaverso entre tantos outros que existirão. Tal situação elevará a prática laboratorial virtual a um novo patamar, uma vez que permitirá a construção de simulações em um ambiente mais próximo da realidade (ilusão da não mediação) e mais propício à comunicação e colaboração. Assim, laboratórios virtuais com tais características poderão permitir o oferecimento de cursos tecnológicos em uma escala muito maior do que a atualmente existente.

\footnotetext{
${ }^{1} \mathrm{O}$ nome Xerox pertence à empresa comercial reconhecida mundialmente como fabricante de copiadoras. Neste artigo utilizou-se este nome, porque efetivamente constitui-se em metonímia (figura de linguagem) utilizada para identificar fotocópias. Acredita-se que a expressão "xerox virtual" identifica, no Brasil, claramente a idéia de utilizar um ambiente virtual de aprendizagem apenas para disponibilizar material de leitura para os alunos.

2 Página para obter relação completa dos exemplos - http://www.simteach.com/slccedu07 proceedings.pdf

http://www.pgie.ufrgs.br/projetos/arca/

${ }^{4} \mathrm{http}: / /$ summit.stanford.edu

${ }^{5} \mathrm{http} / / /$ simergency.stanford.edu/PDFs/SiMErgency_II_Report_1.pdf

${ }^{6} \mathrm{http}: / /$ summit.stanford.edu/research/simtech.html
}

\section{Bibliografia}

ARANGO, F; CHANG, C; ESCHE, S. K. \& CHASSAPIS, C. A scenario for collaborative learning in virtual engineering laboratories. In: Frontiers in education conference - global engineering: knowledge without borders, opportunities without passports, out. 2007, p. F3G-7-F3G-12.

BAINBRIDGE, W. S. The Scientific Research Potential of Virtual Worlds. Science, jul. 2007, vol. 317, n. 5837, p. 472-476.

CLAYPOOL, M \& CLAYPOOL, K. Latency and player actions in online games. Communications of the ACM, 2006, vol. 49, n 11, p. 40-45.

CORTER, J. E.; NICKERSON, J. V.; ESCHE, S. K. \& CHASSAPIS, C ; IM S. \& MA, J. Constructing reality: a study of remote, hands-on, and simulated laboratories. ACM Transactions on Computer-Human Interaction. Vol 14, No 2, ago. 2007. 
FEISEL, L. D. \& ROSA, A. J. The role of the laboratory in undergraduate engineering education. Journal of Engineering Education, Vol 94, No 1, p. 121-130, 2005.

HAMPEL, T.; SELKE, H. \& VITT, S. Deployment of simple user-centered collaborative technologies in educational institutions - experiences and requirements. In: Proceedings of the 14th IEEE International Workshops on Enabling Technologies: Infrastructure for Collaborative Enterprise. 2005. Anais: p. 207-212.

HENDAOUI, A.; KIMAYEM, M. \& THOMPSON, C. W. 3d social virtual worlds: research issues and challenges. Internet Computing, IEEE, 2008, vol 12, n. 1, p88-92.

KEMP, J. \& LIVINGSTONE, D.: Putting a second life metaverse skin on learning management systems. Proceedings of the Second Life Education Workshop at SLCC, San Francisco, 2006, p. 13-18.

LINDSAY, E.; NAIDU, S.; \& GOOD, M. A Different kind of difference: theoretical implications of using technology to overcome separation in remote laboratories. International Journal of Engineering Education. Vol 23, No 4, p. 772-779, 2007.

LOMBARD, M., \& DITTON, T. (1997). At the heart of it all: the concept of presence. Journal of Computer Mediated-Communication. Disponível em: <http://www.ascusc.org/jcmc/vol3/issue2/lombard.htm>. Acesso em: 25 mai. 2008.

MA, J. \& NICKERSON, J. V. Hands-On, simulated, and remote laboratories: A comparative literature review. ACM Computing Surveys. Vol 38, No 3, p. 124, set. 2006.

MORISHIMA, Y.; NAKAJIMA, H.; BRAVE, S.; YAMADA, R.; MALDONADO, H.; NASS, C. \& KAWAJI, S. The Role of Affect and Sociality in the Agent-Based Collaborative Learning System. In: Affective Dialog Systems: Tutorial and Research Workshop. 2004. Springer-Verlag New York Inc. New York, NY. p.265-275.

NEDIC, Z.; MACHOTKA, J. \& NAFALSKI, A. Remote laboratories versus virtual and real laboratories. In: Proceedings of the 2003 33rd annual frontiers in education conference. Boulder, CO. 2003.

NICKERSON, J. V.; CORTER J. E.; ESCHE, S. K. \& CHASSAPIS, C. A model for evaluating the effectiveness of remote engineering laboratories and simulations in education. Computers and Education,. Vol 49, No 3, p. 708-725, Oxford, UK: Elsevier Science Ltda, 2007.

PETERSON, G. D. \& FEISEL, L. D. E-learning: the challenge for engineering education. In: Proceedings, e-Technologies in Engineering Education, A United Engineering Foundation Conference, Davos, Switzerland, 11-16 ago. 2002, p. 164-169. Disponível em: <http://services.bepress.com/eci/etechnologies>. Acesso em: 25 mai. 2008.

STEPHENSON, N. Snow Crash, Bantam Books. New York, NY, 1992.

VYGOTSKY, L. S. Formação Social da Mente. 6.ed. São Paulo: Martins Fontes, 1998. 